1 Universidade Federal de São Paulo (Unifesp), Departamento de Saúde, Clínica e Instituições (DSCl) - São Paulo (SP), Brasil.

fernando.kinker@unifesp.br

2 Universidade Federal de São Paulo (Unifesp), Departamento de Políticas Públicas e Saúde Coletiva (DPPSC) - São Paulo (SP), Brasil.

\section{Abertura de possíveis no cuidado em saúde mental, em momentos de crise}

\author{
Opening up possibilities in mental health care, in times of crisis
}

Fernando Sfair Kinker1, Maria Inês Badaró Moreira²

DOI: $10.1590 / 0103-1104202112814$

RESUMO O objetivo deste artigo é apontar possíveis ações em saúde mental, em momentos de crise, a partir da Rede de Atenção Psicossocial. Utilizou-se de cena ilustrativa para fundamentar a análise, a partir de diferentes concepções sobre o fenômeno. Evidencia-se que concepções hegemônicas e simplificadoras da crise psíquica são centralizadas em sinais e sintomas, e apagam os sentidos do episódio, gerando ações de violência para os envolvidos. Defende-se a busca por respostas complexas, a fim de ampliar possibilidades de entendimento e ação, envolvendo diferentes atores, que estão implicados na produção da cena da crise. Sugere-se uma abordagem amparada em diferentes pontos da rede psicossocial, visto que a manutenção dos laços comunitários é imperiosa e pode se transformar em espaços facilitadores para a aproximação ou manutenção da pessoa na comunidade. Conclui-se que as aberturas possíveis para o acolhimento e as ações em rede encontram limites nas concepções simplificadoras e contraditórias às necessidades das pessoas. Para lidar com a complexidade da crise, necessita-se de outro paradigma, outros olhares, práticas e saberes, que considerem que a pessoa que encarna a crise produz um significado, constrói um saber sobre a vida e sobre a própria crise, e não deve ser colocada no lugar de objeto de intervenção.

PALAVRAS-CHAVE Saúde mental. Centros de Atenção Psicossocial. Sofrimento psíquico.

\begin{abstract}
The objective of this article is to point achievable actions in mental health, in times of crisis, from the Psychosocial Care Network. An illustrative scene was used to support this analysis, from different conceptions about this phenomenon. It is evident that the hegemonic and simplifying conceptions of the psychiatric crisis are centered on signs and symptoms that erase the senses of the episode, and generate acts of violence for everyone involved. The search for complex answers is defended, in order to expand possibilities of understanding and action, involving different actors, that are involved in the production of the crisis's scene. It is suggested an approach supported by different points of the psychosocial network, since the maintenance of the community bonds is imperative and can turn into spaces facilitating the approach or maintenance of the person in the community. It is concluded that the possible openings for the reception and the actions in network find limits in the simplifying conceptions and contradictory to the needs of the people. In order to face the complexity of the crisis, another paradigm is needed, other perspectives, other practices and knowledge that consider that the person who embodies the crisis produces a meaning, builds some knowledge about your life and the own crisis, and should not be placed in the place of intervention object.
\end{abstract}

KEYWORDS Mental health. Mental health service. Stressors, psychological. 


\section{Introdução}

Historicamente, há várias formas de se entender o fenômeno da crise. Todas elas, correlacionadas. O substantivo crise advém do latim crisis, momento de decisão ou mudança súbita; do grego Krísis, que seria a ação ou faculdade de distinguir; pode-se também compreender como um momento decisivo e difícil, por derivação do verbo kríno (grego), que também significa separar, decidir e julgar. Boff' lembra que, em sânscrito, kri pode ser lido como desembaraçar, purificar ou limpar, e que a língua portuguesa conserva as palavras acrisolar e crisol, que têm a mesma origem sânscrita. Para o autor, a crise age como um crisol que purifica o ouro. Deste modo, após um episódio de crise, o ser humano sai purificado, "libertando forças para uma vida mais potente e cheia de sentidos novos"1(27).

A palavra crise tem sido usada para indicar um processo que produz transformações e modifica a pessoa, no sentido de fazê-la superar momentos decisivos da vida; um evento que faz parte do percurso existencial, da relação com o mundo; um ressignificar. Este sentido da crise pode ou não implicar a irrupção de uma experiência dita psicótica. E o que nos interessa é, sobretudo, a que implica isso, por conta de suas consequências, já que em momentos anteriores da história do cuidado em saúde mental, em que havia forte influência de uma cultura hospitalocêntrica, tendo o hospital psiquiátrico como locus para esse tipo de demanda, o momento da crise era um indicativo para se iniciar uma carreira psiquiátrica seguida de internações recorrentes. Ainda que se almeje dizer que tal cena pertence ao passado, o contexto atual de recuo das políticas públicas mostra que o passado pode vir a ser um vislumbre de futuro, tendo em vista o atordoado presente, com ameaças constantes de retorno ao modelo hospitalocêntrico e manicomial, que nunca deixou de assombrar os serviços abertos, mesmo estes assumindo os preceitos da Reforma Psiquiátrica Brasileira.

De qualquer forma, os momentos decisivos de crise podem enriquecer a existência ou torná-la mais contida. O contexto de relações, os recursos de apoio disponíveis coproduzirão os seus efeitos e aquilo que ela poderá se tornar para a vida dos envolvidos. Inclusive, podem determinar se a vivência da crise implicará ou não uma vivência de 'dissociação', como compreendido por muitos profissionais. Aqui, esse termo aparece entre aspas por acreditarmos que somos compostos por fragmentos, e por isto, dissociados de múltiplas formas.

Outra forma de entender a crise é colocá-la como um processo de intenso sofrimento. Isto pode ser percebido no contato com muitas das pessoas que buscam os serviços de saúde mental. As experiências ditas psicóticas geram afetos que levam até os limiares da existência, produzindo intensidades de dor que são difíceis de serem suportadas.

Independentemente da tradução que se faça da crise, importa saber as respostas que ela recebe. É certo dizer que cada leitura que se faz desse momento vislumbra uma resposta.

\section{A crise e a articulação da atenção em rede}

Com a instituição, pelo Ministério da Saúde $(\mathrm{MS})^{2}$, da Rede de Atenção Psicossocial (Raps), muitos foram os ganhos para a pessoa em sofrimento psíquico que vivencia uma situação de crise. Em um modelo de cuidado sistêmico e transversal, viu-se uma ampliação das estratégias e possibilidades de manter o cuidado territorial contínuo. Em um desenho ampliado, puderam-se incluir diferentes composições de equipes trabalhando de modo articulado nos seguintes componentes de atenção: Atenção Básica (AB); Atenção Psicossocial (AP); urgência e emergência; atenção residencial de caráter transitório; atenção hospitalar; estratégias de desinstitucionalização e reabilitação psicossocial.

A ênfase no papel dos Centros de Atenção Psicossocial (Caps) para o cuidado em situações de crise aponta para as influências das concepções de crise que circulam no cotidiano. 
Garcia \& Costa $^{3}$ anunciam importante transmutação na mudança de entendimento da crise e, por conseguinte, mudança de modos de agir da equipe frente à situação. A partir de experiências de abordagem da crise como um sintoma a ser sanado rapidamente por terapias e medicações, ou prevenido pelo poder de polícia, os envolvidos vivenciaram uma modalidade de atenção que não permite compreensão sobre o fenômeno, com tentativas diversas de calar e resolver a situação. Até que, diante de uma experiência de sustentação de uma situação de crise no Caps, o serviço passou a repensar seu modo de organização e os profissionais também se colocaram em análise, a partir dos afetos produzidos. Com essa experiência, os envolvidos passaram a apostar na potência da equipe diante de cenas de crise, tomadas como momentos catalisadores da construção de novos territórios existenciais para esses sujeitos em sofrimento e, consequentemente, para os trabalhadores, que se posicionaram de outro modo, diante da situação.

A articulação da Raps como rede potente vem mostrando que, a partir do momento em que os profissionais passam a vivenciar situações de crise, iniciam uma jornada para construir espaços de manutenção dos laços sociais e familiares das pessoas.

Nessa direção, o apoio matricial tem se revelado importante referência para os profissionais da AB. Lima \& Dimenstein ${ }^{4}$ discutem as ações do apoio matricial na atenção à crise a partir do matriciamento de uma equipe de Caps II, em rodas de conversa com trabalhadores. Identificam a necessidade de promover ampliação na capacidade de acolhimento e cuidado das equipes da Estratégia Saúde da Família (ESF). Nesse relato, o matriciamento se revelou ferramenta apoiadora da atenção à crise, ao prevenir as próprias situações de crise ou abordá-las antes que se agravassem. Esta forma evita manejos mais invasivos, tais como: utilização da polícia, uso de força física, conduções involuntárias para a emergência e internação hospitalar.

O trabalho desenvolvido e a aproximação com o mundo vivido dos usuários em crise confirmam serem os caminhos para o fortalecimento da Raps. Diferentemente deste conjunto articulado de ações, as dificuldades de trabalho de algumas equipes dos Caps também são evidenciadas. Willrich et al. ${ }^{5}$ destacam e questionam o papel da polícia, pois esta vai na contramão de um modo de cuidar que prevê o trabalho articulado em rede. Uma análise sobre os sentidos presentes nas práticas de profissionais de um Caps, produzidos pelas formas de lidar e se relacionar com o sujeito em crise, destaca a contenção e os sentidos construídos em torno dessa prática. Os dados também chamam a atenção para os diferentes posicionamentos dos profissionais em relação a esse tipo de ação: os trabalhadores indicam a Polícia Militar (PM) como protagonista no cuidado da crise e questionam a responsabilidade da equipe, de cuidar do usuário também nesse momento. Por evidente descompasso, defende-se como necessária a construção de práticas coletivas para a atenção à crise, embasadas em relações contratuais, no respeito à singularidade e à subjetividade dos sujeitos.

Nessa mesma direção, os estudos de Andrade, Zeferino e Fialho ${ }^{6}$ apontam que as contenções medicamentosa e mecânica, além da internação, aparecem como ações para redução dos sintomas, com desvalorização do sofrimento, deixando a pessoa em segundo plano. Estudos como estes revelam certa distância entre a realidade de alguns serviços e o preconizado pela política de saúde mental no País. Além disto, demonstram graves implicações na prática do cuidado em saúde mental e recuos evidentes na consolidação de formas de cuidado na comunidade, a partir da AP.

Em outra ponta da Raps, prevê-se o atendimento de urgência realizado por equipe de Serviço de Atendimento Móvel de Urgência (Samu), intervindo em situações de crise psíquica. Uma análise de Almeida et al. ${ }^{7}$ sobre este tipo de intervenção destaca a emergência de três ideias centrais: a alteração de comportamento e instabilidade psicológica; a manifestação com presença de alucinações e agressividade; e a intervenção que ocorre com 
contenção física, medicamentosa e encaminhamento. $\mathrm{O}$ estudo afirma que a concepção dos profissionais sobre a crise está pautada em uma perspectiva positivista da psiquiatria e, em consequência deste modelo de compreensão, a atenção pré-hospitalar segue medidas protocolares no atendimento à pessoa em crise psíquica, distantes dos princípios determinados pelo paradigma psicossocial.

Estudo realizado por Brito, Bonfada e Guimarães $^{8}$, sobre o atendimento prestado às crises psíquicas pelos profissionais de saúde do Samu, destaca a participação da PM nas ocorrências psiquiátricas como característica comum desse tipo de atendimento em urgências. Os autores apontam a necessidade de capacitação para vencer elementos associados à prática manicomial, como o uso da força coercitiva, exercida com o auxílio de policiais militares, que ainda estão presentes no ideário e na assistência prestada pelos profissionais entrevistados, embora defendam que a assistência mantenha os laços sociais, ambientais e afetivos dos sujeitos, evitando medidas violentas, repressoras ou excludentes. Este parece ser o elemento central para a compreensão dos achados sobre signos e significados de crise atribuídos pelos familiares e profissionais em saúde mental, exposto por Lima et al. ${ }^{9}$, uma vez que não há diferença entre as concepções de profissionais e familiares acerca da crise, já que ambos trazem significados negativos que suplantam os positivos, evocando os conceitos de sujeição à doença, incapacidade de interação social racional e periculosidade da pessoa tomada como doente. Por outro lado, Souza, Pinho e Cortes ${ }^{10}$ assinalam que o fato de o hospital geral ser a única referência para alguns serviços móveis sustenta a desvalorização ou o desconhecimento das ações dos Caps como serviços comunitários e territoriais no cuidado às crises psíquicas, pois equipes dos serviços indicam que o papel do Samu acaba por direcionar o ponto da rede a ser acessada pela pessoa.

Os referidos estudos ${ }^{5-10}$ apontam que, de modo geral, a resposta à situação de crise é fruto de um modo hegemônico de compreender o sofrimento psíquico e as ações em saúde mental. Forma secular, naturalizada, que vem como em uma correnteza (embora seja uma resposta construída historicamente), é a intervenção dos dispositivos da ordem, em uma combinação e parceria entre as forças de segurança (polícia, justiça etc.) e as especialidades de saúde, que são legitimamente instituídas como aquelas que podem tratar e conter aquilo que foi traduzido como doença, ou como transtorno que está presente exclusivamente dentro da pessoa, um transtorno dito endógeno.

Mas há, também, outras perspectivas transformadoras. A experiência italiana em Trieste, por exemplo, demonstra na prática a possibilidade de transformar o episódio de crise. $\mathrm{O}$ manejo precoce das situações de crise tem sido realizado no domicílio com a inserção de familiares em todo o processo, o que vem apontando maior facilidade de manter o cuidado posterior. A equipe que aborda as situações de crise em casa realiza um trabalho em quatro fases: 1) inicia com a avaliação, 2) seguida de construção conjunta de um plano terapêutico, 3) envolver os familiares, até a fase 4) a ampliação de cuidados em equipamentos de acolhimento, se for o caso. O trabalho vem reduzindo consideravelmente a utilização de espaços hospitalares ou de acolhimento integral'1.

Contudo, embora seja uma experiência com respostas muito positivas, tal perspectiva de lidar com a crise ainda é algo a ser consolidado no Brasil, de maneira a transformar os modos hegemônicos de cuidar da crise nos serviços de saúde mental do país. É o que corrobora o estudo de Dias, Ferigato e Fernandes ${ }^{\mathbf{1 2}}$, que realizaram análise de protocolos e documentos institucionais em saúde mental, à luz da abordagem sociotécnica, apontando importantes dicotomias emergentes dos processos de atenção à crise.

Assim sendo, a forma hegemônica de lidar com a crise parece ter veios comuns: violência, contenção, limite e manutenção de um circuito psiquiátrico. 
Partindo desse contexto, o presente artigo objetiva apontar e discutir possíveis ações de enfrentamento de desafios presentes na atenção à crise, no âmbito da Raps. Para isto, pretende-se discutir uma visão do fenômeno da crise, que a coloca como o desenrolar de uma cena composta por múltiplos atores e cenários. Uma cena longitudinal, em movimento, cujo desdobramento não pode ser definido $a$ priori, dependendo de respostas que a coproduzem, em um movimento recursivo no qual o efeito retroage sobre a causa.

\section{Material e métodos}

Este manuscrito se constitui a partir de um caso construído para uso didático em ambiente de formação e educação permanente de profissionais de saúde, a partir da reunião de diversos fragmentos de histórias vividas pelos autores. Trata-se de uma narrativa elaborada a partir de diferentes personagens e cenários, sem se fixar em uma situação ou pessoa específica. Os autores foram tomados pela necessidade de compartilhar tal experiência, entendida, na perspectiva de Bondía ${ }^{13}$, como uma oportunidade de nos abrirmos para que algo nos toque, admitindo um gesto de interrupção que possibilite parar para pensar sobre o cotidiano profissional; parar para olhar e demorar nos detalhes, nas histórias; parar para escutar e compartilhar esse olhar, de modo a inaugurar um novo sentir e, assim, um fazer repleto de novos sentidos. Os autores-narradores, transpassados pela experiência, se interessam em provocar reflexões, a partir de vivências comuns a vários trabalhadores de serviços, e, por terem sido atravessados por essas histórias, se perceberam comprometidos em narrá-las, uma vez que, como define Benjamim 14(201): "o narrador retira da experiência o que ele conta [...] e incorpora as coisas narradas à experiência do ouvinte".

Assim emergiu uma narrativa polifônica, construída a partir de conversas, debates e diferentes oportunidades de diálogo entre os autores no cotidiano profissional, em ambiente de docência, supervisão e atuação profissional em serviços de saúde. A cena apresentada elucida um somatório de situações cotidianas comuns a muitos serviços de saúde. A personagem poderia ser encontrada em um serviço com as características trazidas pela narrativa, assim como poderia estar silenciada em espaços confinados ainda existentes.

Essa ilustração está sendo usada como instrumento de apresentação de uma das formas possíveis de abordagem do que na área de saúde mental convencionou-se chamar de crise. Optou-se por inserir a narrativa em um Caps III, organizador de ações territoriais, com funcionamento 24 horas/dia e a função de articular a relação dos seus usuários com os territórios de existência, produzindo agenciamentos e experiências que enriqueçam as redes de relações, aumentem o poder contratual e modifiquem valores relacionados ao sofrimento psíquico ${ }^{2}$. Optou-se por este desenho por ser condizente com a manutenção de cuidados comunitários previstos na Reforma Psiquiátrica Brasileira ${ }^{15}$.

Aliada à proposta de aberturas possíveis, a escolha de construir uma narrativa para este artigo produz sintonia com um desejo maior de fortalecer a perspectiva da desinstitucionalização, ampliando os olhares em direção às pessoas e suas histórias, como fizeram Kossah, Moreira e Braga-Campos ${ }^{16}$ em recente artigo.

Este texto está voltado para fomentar a criação de novos estratos, significações abertas, e assim buscar romper com a relação de causa-efeito, com uma perspectiva que desvaloriza as histórias de vida e torna as narrativas silenciadas, típica do modo de operar do aparato manicomial.

\section{A crise de Pétala}

Pétala sente-se morta. Deitada na cama, percebe as batidas do coração como trilhas sonoras de um universo distante: sente-se em uma outra dimensão. $\mathrm{O}$ ar quente que vem de sua janela, 
como um jorrar de chamas, indica que seu corpo está a se desintegrar. O cheiro de suor está mais ácido e, por isto, ela tem a certeza de que algumas partes de seu corpo já não existem mais. As únicas imagens que consegue destacar são aquelas que vêm como relampejos quando seus olhos estão abertos. Estes, agora fechados, percebem um feixe de elétrons, como uma onda sobre outra, surgindo em cores diversas. Pétala não responde ao chamado de sua irmã, cuja cama fica ao lado da sua.

A irmã observa que as pálpebras de Pétala fazem pequenos movimentos, parecem trêmulas. $\mathrm{O}$ fato de o ar estar sendo absorvido por Pétala somente é perceptível pelo tato, quando se colocam os dedos à frente de suas narinas. O mesmo se pode dizer do movimento dos pulmões e do peito pulsante: o coração está a bater. Assim, a irmã entende rapidamente que Pétala 'morreu' novamente. Isto ocorre quando as coisas não vão bem: porque ela sente certo vazio, porque o dia estava escuro, porque sua mãe não as foi visitar, porque volta a lembrar de quando podia ter um trabalho e um dia pleno de descanso; ela simplesmente volta a 'morrer'. Mas o que é este morrer de Pétala?, pergunta-se a irmã. É um morrer que insiste em se repetir ao longo dos anos. A irmã aprendeu recentemente uma nova forma de lidar com a 'morte' de Pétala: se antes chamava a ambulância, esta chamava a polícia, e ambas a levavam ao pronto-socorro, que a despachava para o hospital psiquiátrico, agora, a irmã liga para Sandra, assistente social do Caps III de Paraíso dos Vivos, cidade do interior de um grande estado.

Naquele dia, ao ser acionada, Sandra foi visitar as irmãs e tentou conversar com a recém-falecida. Normalmente, tais encontros têm envolvido falas e contato físico, mas Pétala sempre se mantém desfalecida. Se lhe levantam o tronco, volta à posição horizontal tão logo a soltam, e mantém-se muda e com os olhos cerrados. Sandra, mais uma vez, diz a Pétala: "OK, Pétala! Estou ente ndendo que você quer que a levemos ao Caps, certo? Então, vou chamar a ambulância...”.
O trajeto até o Caps é tranquilo. Embora os atendentes da ambulância reclamem de terem que levar novamente um morto-vivo ao Caps, pois consideram que há coisas mais importantes a fazer, Sandra e a irmã de Pétala seguem apoiando o corpo dela dentro da ambulância, conversando com ela, mesmo sem ela responder. Já no Caps, a equipe vai refletindo sobre as repetidas 'mortes' de Pétala, e percebe que têm sido sempre diferentes, seja na duração, seja nos sinais que ela apresenta quando do renascimento. Sempre parece haver uma nova Pétala ressurgindo da 'morte'. Pétala coloca novos desafios à equipe, pois suas 'mortes' são mensagens de que sua produção de mundo está precisando ser refeita, e que isto depende dos atores que compõem seu mundo; parece ser necessário mudar tal cena. A forma como a 'morte de Pétala' irrompe parece revelar que algo à sua volta precisa mudar e, portanto, impõe diversas dúvidas a todos que a cercam. E, daquela vez, o renascimento de Pétala se deu quando foi inserida em um trabalho, por meio da participação em um projeto de economia solidária desenvolvido pelo Caps, em parceria com uma organização não governamental e com pessoas do movimento social de moradia instalado no bairro.

Não é seguro dizer se Pétala vai ou não experimentar outros momentos de conflito e outras 'mortes', mas estas, por mais contraditórias que pareçam, fazem parte da vida, e têm sido, no caso dela, a condição para que o mundo sofra uma metamorfose. De certo, quanto mais valer a pena estar viva, menos Pétala morrerá.

\section{Outra forma de conceber a crise e produzir outras ações}

A história de Pétala remete a situações cotidianas que poderiam ter ocorrido em qualquer um dos serviços de saúde mental, e ajuda a identificar a crise situada no contexto das pessoas 
envolvidas: a pessoa em sofrimento, sua irmã e a equipe que a acolhe no serviço. Diante dos desafios atuais para a efetivação do cuidado das pessoas em situação de crise, podemos também entender a crise como uma situação processual - como a cena vivida por Pétala e sua irmã -, um corte no tempo, dentro de um longo processo de existir, que está em construção a partir das relações vivenciadas pela pessoa. Portanto, não está 'dentro' da pessoa, em uma vivência 'interna' a ela, não se trata de uma experiência individual, mas constituída no 'entre' das relações. Se tomarmos a crise como cena de uma rede de relações em movimento, como expressão de determinado processo relacional, ou como o processo em si, a crise passa a ser fato social, implicando cenas sociais, atores sociais, contextos sociais, relações de saber e poder, produção de realidades.

Se entendermos a crise por essa via, ela se torna muito complexa, e as respostas dadas a ela ultrapassam a simples contenção, a anulação, o enfraquecimento do acontecimento, da intensidade dos afetos produzidos (tentamos arrefecer a crise para diminuir o sofrimento daquele que a expressa, mas, também, porque suportamos pouco a angústia de entrar em relação com alguém que vive essa experiência).

Desse modo, as respostas que tais situações recebem, como já dito acima, ajudam a coproduzir a crise. Ou seja, a partir do momento em que ela chega, através das pessoas que chegam aos serviços (ou às quais os serviços vão atender em domicílio), já se começam a coproduzir a crise e seus significados. Isto é importante perceber, porque remete a ter um olhar crítico e reflexivo sobre as ações a serem desenvolvidas, já que quaisquer que elas sejam, estarão coproduzindo a cena da crise.

Quando comumente se defende a capacitação para avançar em diferentes modos de agir junto às pessoas em situação de crise e superar as práticas manicomiais, lembramos que a ideia de 'capacitar para atender à crise' não pode ser equivalente à de transformar o modo de compreender o momento da crise dentro de um contexto amplo e complexo da vida. Pois essa transmutação não ocorre apenas com a capacitação para o trabalho, tal como visto em pesquisa referente ao curso Crise e Urgência em Saúde Mental, para trabalhadores da Raps com formação em nível superior, oriundos de diversas regiões do Brasil, selecionados pelo $\mathrm{MS}^{6}$.

Nesses anos de trabalho em educação permanente para trabalhadores do Sistema Único de Saúde (SUS), pode-se afirmar que não se trata de aumentar o número de horas de estudo e capacitação para melhor agir sobre a crise e sim, de transmutar a compreensão sobre o que é, de fato, a crise, ou seja, mudar o objeto a ser visto. E isto se dá com a prática reflexiva e coletiva.

Ao tomarmos o caminho de uma pessoa até sua chegada a um pronto-socorro psiquiátrico, muitas situações já ocorreram e contribuíram para compor o quadro que revela a crise: aquilo que irrompe a partir de seus nexos existenciais, relacionais, nos territórios de existência da pessoa, é interpretado e transformado em outra coisa quando a polícia e a ambulância são mobilizadas e comparecem ao domicílio. Os acontecimentos daí decorrentes, a abordagem, o trajeto até o pronto-socorro e a própria abordagem ali realizada acrescentarão outros significados e transformarão, através de simplificações, a complexidade da crise.

Essa cadeia de simplificação sempre é traduzida pelos códigos da doença, pelos sinais e sintomas, geralmente apagando os rastros de sentido ou o fio da meada que poderia ampliar e tornar complexa a cartografia do fenômeno. Inverter esse modo de fazer, para outro que se oriente em buscar respostas complexas e críticas para o fenômeno da crise, passa por um olhar e uma prática crítica que aborde a questão, ampliando as possibilidades de entendimento e tradução, envolvendo os atores implicados na produção da cena de crise. Essa ação só será possível se houver uma compreensão de que tal cena é construída a muitas mãos, envolvendo contextos reais e complexos de vida e relações reais, para além de uma vivência da doença e do fenômeno em si.

Para lidar com a crise de forma complexa é necessário que haja outro paradigma, 
bem como outros olhares, outras práticas, outros saberes que considerem que a pessoa que encarna a crise é um ator essencial na produção de significado; que ela produz um saber sobre a vida e sobre a crise, e não deve ser colocada no lugar de objeto de intervenção.

A Raps, como rede comunitária e territorial, em articulação com as outras redes de sociabilidade do território existencial das pessoas e grupos sociais, tem a possibilidade de exercer outra abordagem à crise. Essa abordagem vem como parte de uma construção mais geral de projetos de vida e de percursos de ampliação e transformação das cenas sociais, que invalidam e expelem a experiência do sofrimento, e tudo o que ela tem de revelador.

\section{Abordagem à crise e a aposta da vida em liberdade}

Abordar as situações de crise no contexto dos serviços da Raps é algo complexo, pois implica a permanente comunicação e interação com os elementos que compõem o cotidiano de relações entre os atores sociais. Podemos entender as relações sociais como relações de poder, e o poder como a energia que circula e é produzida no choque entre os corpos. O poder ${ }^{17,18}$, desta forma, está presente em todos os lugares, e seu exercício é o verdadeiro produtor da realidade, ou das cenas sociais. Neste sentido, todas as relações são relações de poder.

A primeira questão a ser considerada na abordagem à crise no contexto da Raps é trabalhá-la sob uma perspectiva ampla, que busque aberturas de entendimento. Este processo demanda ampliar as formas e fontes para o entendimento da situação, de modo articulado à vida concreta das pessoas. Não se trata de um momento isolado ou um acontecimento fora da vida, por isto, é importante enriquecer os fluxos de inteligibilidade, produzir pistas, elencar interpretações móveis que se modifiquem a todo o momento, com o intuito de construir hipóteses que favoreçam o exercício de poder da pessoa que manifesta o sofrimento.
Como todo exercício de inteligibilidade é uma escolha de determinado(s) caminho(s) mesclado(s), procurar os caminhos que favoreçam o usuário dos serviços já representa uma importante mudança de cena e de transformação das relações de poder. Essa ação provoca um desvio importante no caminho a seguir posteriormente.

Uma análise reflexiva-racional nem sempre possibilita a compreensão dos fenômenos. Antes disto, há uma espécie de 'consciência pré-reflexiva', ou, nas palavras de Merleau-Ponty, uma 'consciência perceptiva' ${ }^{\prime 9}$. E isso, de certa forma, foi exigido de Sandra na cena acima:

Para saber o que significa o espaço mítico ou esquizofrênico, não temos outro meio senão despertar em nós, em nossa percepção atual, a relação entre sujeito e seu mundo, que a análise reflexiva faz desaparecer. É preciso reconhecer, antes dos 'atos de significação' do pensamento teórico e tético, as 'experiências expressivas'; antes do sentido significado, o sentido expressivo; antes da subsunção do conteúdo à forma, a 'pregnância' simbólica da forma no conteúdo19(391).

Para construir uma inteligibilidade mutante e rica é necessário confiar na sensibilidade e na lapidação do entendimento que os afetos produzem em todos os envolvidos: usuários, familiares ou acompanhantes, e nos demais atores envolvidos em cada uma das situações, como também trabalhadores da área da saúde. A sensibilidade crítica entra aqui como um instrumento de saber e de construção de uma nova realidade. $\mathrm{O}$ que sente e como reage cada ator envolvido em uma situação de crise? O que mobiliza as nossas decisões e os nossos encaminhamentos? Essas são questões fundamentais de autocrítica, que delineiam o caminho que a situação de crise tomará.

A atenção flutuante sobre a totalidade da cena, e não apenas sobre a pessoa que expressa um mal-estar coletivo, permite, então, que se possam rascunhar inúmeros desfechos, a serem construídos flexivelmente. 
Se a crise está entre as pessoas, nas relações, é neste 'entre' que os serviços devem intervir e provocar alguma transformação; construir amplo leque de ações que se coloquem nesse espaço do 'entre as pessoas', para que cada um dos envolvidos possa se ver e ressignificar as situações que produzem tal crise. Tomando a perspectiva da complexidade ${ }^{20}$ como uma dimensão da existência e do entendimento, que vai além de toda a simplificação e disjunção dos saberes diversos, podemos dizer que, nesse 'entre as pessoas', se estabelece uma unidade complexa entre, pelo menos, duas lógicas, que se alimentam uma da outra - a racionalidade e a percepção afetiva -, podendo se completar ou instituir novos embates, fundando o que poderíamos chamar de 'racionalidade aberta'.

Pode ser também compreendida como momento decisivo, que convoca ações de diferentes atores - desde trabalhadores na abordagem inicial e no acolhimento, passando pelos cuidados próximos e quentes, até a manutenção do plano de cuidado e a construção de projetos de vida, nos Projetos Terapêuticos Singulares (PTS). Sendo assim, a continuidade do cuidado deve estar prevista, desde a recepção e o acolhimento inicial, como um alvo orientador a ser alcançado.

Esse é o principal motivo para que tal momento esteja inserido no contexto dos Caps, como serviços abertos na comunidade. Uma vez ausentes dessa cena os serviços territoriais, corre-se o risco da perda do fio que poderia sustentar o caminho do cuidado a ser implementado à frente.

Portanto, deve-se ampliar esse debate no cotidiano de todos os serviços de saúde da rede, de modo que a preocupação com o acolhimento à crise não fique restrita aos Caps III ${ }^{21}$, ainda que seja fundamental que este serviço esteja presente. Mas que também se torne uma cena protagonizada, em íntima parceria, por múltiplos atores, potencializando as respostas e os possíveis desfechos. As investidas de cada um dos serviços podem parecer pequenos avanços, mas o grande ganho com o acolhimento da crise em rede será essencial para o cumprimento de um dos objetivos da política de saúde mental territorial, que seria evitar as internações e modificar as cenas que geram a exclusão e a invalidação, anulando as contradições sociais.

A flexibilidade e a prontidão dos serviços podem ampliar o potencial de transformação, calcado na confiança que os atores do território fortalecem junto à equipe; uma prática consistente e que saiba lidar com as contradições do cuidar e do controlar, que pode potencializar diversas transformações ${ }^{\mathbf{1 6 , 1 8 , 2 2}}$.

A aproximação e a presença sensível e eficiente da equipe geram a necessidade de deslocamentos, sejam físicos (como ir ao encontro da pessoa em qualquer lugar), sejam temporais. O uso de estratégias diversas de aproximação, o envolvimento de atores importantes para a pessoa em sofrimento nos momentos de crise, como sugerem Dell'acqua \& Mezzina ${ }^{23}$, constroem a possibilidade de entender que mesmo as medidas mais fortes, desde que dialogadas e compartilhadas com a pessoa que sofre, traduzir-se-ão em manifestações de cuidado e preocupação, compartilhamento de angústias e tristezas, uma continência na potência de vida que se torna coletiva, em nome do acolhimento: estaremos amarrados juntos, e logo nos soltaremos, juntos.

Geralmente, quando as medidas fortes ocorrem, isto significa que algo não está indo bem, e que é necessário repensar. Mas é melhor e mais correto responsabilizar-se pela pessoa, mesmo nesses momentos, do que delegar isso a outros lugares. Não é desejável ceder ao risco da liberdade abstrata e do abandono.

A possibilidade de a mesma equipe cuidar da pessoa, estando ela em crise ou não, também possibilita produzir novos nexos, transformar as cenas, agregar elementos novos nesse processo de construção e evitar a ruptura, a violência e a reprodução de cenas que a anulem ou a invalidem, já que quem atende apenas à crise acaba por produzir uma simplificação e uma simples busca pelo arrefecimento.

A imprevisibilidade e as transformações na vida das pessoas são dois aspectos 
fundamentais para seu manejo e, por isto, pode-se defender algum investimento em tecnologias leves-duras e leves ${ }^{24}$. Esse tipo de ação pode possibilitar a construção de vínculos e a intensificação de cuidados nos momentos de crise. Certo é que o arranjo e o equilíbrio entre essas formas de tecnologias abarcam os diferentes tipos de modelos de atenção à saúde, que podem coadunar com as premissas da desinstitucionalização e do cuidado em liberdade.

Assim, é possível produzir outras possibilidades de acolhimento ou hospitalidade integral às situações de crise, supervisionadas e mediadas pelos Caps, tais como: famílias acolhedoras; repúblicas de usuários; o profissional do serviço de saúde dormir na casa do usuário etc. A inventividade e a proliferação de alianças, a partir de uma visão ampla do fenômeno da crise, entendendo-a como algo do âmbito do coletivo, proporcionarão respostas inusitadas, que, mais do que acolher à crise, transformarão os envolvidos, constituindo novas cenas.

Ainda pode-se compreender esse momento que chamamos de crise como uma ruptura, uma fratura do processo de vida. A fratura diz respeito não só a um movimento realizado por aquele onde está identificada, localizada, concentrada a crise, mas às respostas que tais situações receberam. Ou seja, à coprodução a qual já nos referimos.

Nesse sentido, a crise também pode ser compreendida como um tipo de organização momentânea que se tem à disposição no momento em que outros recursos psíquicos foram utilizados. A crise pode ser um ponto decisivo para uma pessoa que não vislumbra outros modos de enfrentar uma experiência de sofrimento. Portanto, a crise é um episódio decisivo para a continuidade do cuidado e, sobretudo, para a manutenção do indivíduo em seu espaço existencial e afetivo. Desse modo, a estratégia inicial de acolhimento à crise $\mathrm{e}$ seu manejo vão determinar o caminho a ser trilhado pela pessoa que está em sofrimento psíquico intenso e pelos demais em seu entorno. Assim, deve-se antever a solução de continuidade do cuidado a posteriori, e não o perder de vista.

Sendo um ponto decisivo de rupturas vivenciado pela pessoa, não há retorno possível. Assim, dista sobremaneira da expectativa equivocada de um restabelecimento esperado pelos familiares e pelas pessoas do entorno. A partir deste ponto, só há o caminho à frente, a seguir. Por isto, as ações empreendidas nesse momento devem ser orientadas para um ponto à frente da vida dessas pessoas e não como uma tentativa malsucedida de retomar a vida como antes.

A crise vai se tornando um processo que compõe determinado percurso de vida, vai se produzindo como um brotar do sentido em direção ao fortalecimento da vida. Ressignificase o sofrer, alteram-se os elementos que produzem a cena do sofrimento, aumentando a potência de agir.

Como nos diz Espinosa ${ }^{25}$, somos corpos constantemente afetados pelas relações que nos constituem como intensidades subjetivas, $\mathrm{e}$ essas afetações aumentam ou diminuem nossa potência de agir. Se pudermos ser afetados pelas forças que lutam contra o desespero e a miséria, nos tornaremos mais potentes e comporemos com mais energia a natureza a que pertencemos, e que nos forma enquanto a formamos.

Essa política da relação entre os corpos, que podemos chamar de relações de poder, nos investe de energia e nos metamorfoseia, transformando também o sofrimento. O sofrimento é, sobretudo, uma questão política, que tem a ver com a produção de corpos potentes ou impotentes. Corpos potentes são aqueles que se compõem com os elementos que os transformam, no sentido de lhes intensificar a energia vital. Por isto, o saudável é aquele que apresenta uma intensidade de vida, e estar em crise pode ou não possibilitar este aumento de intensidade.

\section{Conclusões}

O que está em jogo na mudança das cenas relacionadas à crise é a forma de entender o sofrimento psíquico como uma articulação 
das dimensões da vida de uma pessoa. Para essa transformação no modo de compreender a crise e também de empreender um plano de ação que se inicia já nesse momento, é necessária uma ruptura epistemológica. Tratase da construção de um modo diferente de compreender, aproximar, construir aberturas e ampliar o espaço de manejo da situação com os demais envolvidos.

Trata-se, sobretudo, de se abrir para construções coletivas, de um saber que não se sobreponha a outro. É também fundamental aceitar trabalhar com a incerteza, abrir-se para pequenas aventuras e ousadias. E, sobretudo, compreender que há uma chance para a criatividade, e de se poder ir vivendo em paz com as crises dos serviços, aprendendo com elas.

Uma mudança epistemológica dessa envergadura implica transformar o modo como todos os envolvidos concebem esse momento.
São mudanças importantes nos profissionais e nos serviços, mas também uma forma pedagógica de alterar o modo como a família e o entorno lidam com esse momento inserido no modo de viver de uma pessoa.

E, por fim, é fundamental que os usuários mudem e consigam traduzir esse momento para as pessoas à sua volta. Assim, todos seriam capazes de fazer um caminho diferente, e as cenas das crises teriam outros desfechos. A fórmula transformadora permite que todos enriqueçam o olhar, a sua existência pessoal, sua relação com o trabalho e com a vida.

\section{Colaboradores}

Kinker FS (0000-0002-3733-9126)* e Moreira MIB (0000-0001-5798-2023)* contribuíram igualmente para a elaboração do manuscrito. 


\section{Referências}

1. Boff L. Crise - oportunidade de crescimento. Petrópolis: Vozes; 2010.

2. Brasil. Ministério da Saúde. Portaria $n^{0} 3.088$, de 23 de dezembro de 2011. Institui a Rede de Atenção Psicossocial para pessoas com sofrimento ou transtorno mental e com necessidades decorrentes do uso de crack, álcool e outras drogas, no âmbito do Sistema Único de Saúde (SUS). Diário Oficial da União. 21 Maio 2013

3. Garcia AM, Costa HCP. A crise no cotidiano dos serviços de saúde mental: o desafio de experimentar desvios e favorecer a potência inventiva. Saúde debate [internet]. 2014 [acesso em 2020 set 13]; 38(101):399408. Disponível em: http://www.scielo.br/ scielo.php?script $=$ sci_arttext $\&$ pid $=$ S0103$-11042014000200399 \& \operatorname{lng}=\mathrm{en}$.

4. Lima M, Dimenstein M. O apoio matricial em saúde mental: uma ferramenta apoiadora da atenção à crise. Interface (Botucatu) [internet]. 2016 [acesso em 2020 set 13]; 20(58):625-635. Disponível em: http://www.scielo.br/scielo.php?script=sci_ arttext\&pid=S1414-32832016000300625\&lng=en .

5. Willrich JQ, Kantorski LP, Antonacci MH, et al. Da violência ao vínculo: construindo novos sentidos para a atenção à crise. Revista Brasileira de Enfermagem [internet]. 2014 [acesso em 2020 set 13]; 67(1):97-103. Disponível em: http://www.scielo.br/scielo.php?script=sci_arttext\&pid=S0034$-71672014000100097 \& \operatorname{lng}=$ en.

6. Andrade K, Zeferino MT, Fialho MB. Articulação da rede de atenção psicossocial para o cuidado às crises. Psicologia em [internet]. 2016 [acesso em 2020 set 14]; 21(2):223-3. Disponível em: https://periodicos.uem. br/ojs/index.php/PsicolEstud/article/view/31269.

7. Almeida $\mathrm{AB}$, Nascimento ERP, Rodrigues J, et al. Atendimento móvel de urgência na crise psíquica e o paradigma psicossocial. Texto \& Contexto Enfermagem [internet]. 2015 [acesso em 2019 ago 25]; 24(4):1035-43. Disponível em: http://www.scielo.br/ pdf/tce/v24n4/pt_0104-0707-tce-24-04-01035.pdf.

8. Brito AAC, Bonfada D, Guimarães J. Onde a reforma ainda não chegou: ecos da assistência às urgências psiquiátricas. Physis [internet]. 2015 [acesso em 2021 mar 30]; 25(4):1293-1312. Disponível em: http://www. scielo.br/scielo.php?script=sci_arttext\&pid=S0103$-73312015000401293 \& \operatorname{lng}=\mathrm{en}$.

9. Lima M, Jucá VJS, Nunes M, et al. Signos, significados e práticas de manejo da crise em Centros de Atenção Psicossocial. Interface (Botucatu) [internet]. 2012 [acesso em 2021 mar 30]; 16(41):423-434. Disponível em: http://www.scielo.br/scielo.php?script=sci arttext\&pid=S1414-32832012000200011\&lng=en.

10. Souza AS, Pinho PH, Cortes HM. Estratégias de atendimento à crise psíquica por um serviço de atendimento móvel de urgência. Jounal nurs. Health. [internet] 2019 [acesso em 2021 mar 30]; 9(1):e199109. Disponível em: https://periodicos.ufpel.edu.br/ojs2/ index.php/enfermagem/article/view/15019.

11. Sade RMS, Goljevscek S, Corradi-webster CM. Intensive home support for mental health crises: experience of the Trieste territorial crises team, in Italy. Saude soc. [internet]. 2020 [acesso em 2020 out 17]; 29(3):e190831. Disponível em: http://www. scielo.br/scielo.php?script=sci_arttext\&pid=S0104-12902020000300304\&lng=pt.Epub14-Ago 2020.

12. Dias MK, Ferigato S, Fernandes ADSA. Atenção à Crise em saúde mental: centralização e descentralização das práticas. Ciênc. Saúde Colet. [internet]. 2020 [acesso em 2020 out 13]; 25(2):595-602. Disponível em: http://www.scielo.br/scielo.php?script=sci arttext\&pid=S1413-81232020000200595\&lng=pt. Epub03-Fev-2020.

13. Bondía JL. Notas sobre a experiência e o saber de experiência. Rev Bras Edu [internet]. 2002 [acesso em 2019 ago 13]; 19:20-28. Disponível em: http://www. scielo.br/scielo.php?script=sci_arttext\&pid=S1413$-24782002000100003 \& \operatorname{lng}=\mathrm{en} \& \mathrm{nrm}=$ iso. 
14. Benjamim W. Obras escolhidas: magia e técnica, arte e política. São Paulo: Brasiliense, 1985.

15. Brasil. Ministério da Saúde. Portaria n 336 , de 19 de fevereiro de 2002. Estabelece as modalidades de CAPS. Diário Oficial da União, Brasília, DF. 19 Fev 2002.

16. Koosah J, Moreira MIB, Braga-Campos FC. Construindo histórias em tessitura lenta: desinstitucionalização e narrativas em pesquisa. Saude soc. [internet]. 2019 [acesso em 2020 out 17]; 28(3):29-39. Disponível em: http://www.scielo.br/scielo.php?script=sci arttext\&pid=S0104-12902019000300029\&lng=pt. Epub07-Out-2019.

17. Foucault M. Microfísica do poder. 26. ed. Rio de Janeiro: Graal; 2008.

18. Basaglia F. Escritos Selecionados em saúde mental e reforma psiquiátrica. Rio de Janeiro: Garamond; 2005.

19. Merleau-Ponty M. Fenomenologia da percepção. 2. ed. São Paulo: Martins Fontes; 1999.

20. Morin E. O método 4: As ideias, hábitat, vida, costumes, organização. 3. ed. Porto Alegre: Sulina; 2002.
21. Brasil. Ministério da Saúde, Secretaria de Atenção à Saúde, Departamento de Ações Programáticas Estratégicas. Saúde mental no SUS: os centros de atenção psicossocial. Brasília, DF: MS, 2004.

22. Kinoshita RT. Em busca da cidadania: Desinstitucionalização de um hospital psiquiátrico. In: Braga-Campos FC, Henriques CMP, organizadores. Contra a maré à beira-mar: A experiência do SUS em Santos. São Paulo: Scritta; 1996. p. 39-49.

23. Dellacqua G, Mezzina R. Resposta à crise: estratégia e intencionalidade da intervenção no serviço psiquiátrico territorial. In: Amarante P, organizadores. Archivos de saúde mental e atenção psicossocial. Rio de Janeiro: Nau Editora; 2005. p. 161-194.

24. Merhy EE. Em busca de ferramentas analisadoras das tecnologias em saúde: a informação e o dia a dia de um serviço, interrogando e gerindo trabalho em saúde. In: Merhy EE, Onocko R, organizadores. Agir em saúde: um desafio para o público. São Paulo: Hucitec; 2006. p. 113-150.

25. Espinosa B. Ética e tratado político. São Paulo: Nova Cultural; 2005.

\footnotetext{
Recebido em 28/10/2019

Aprovado em 24/10/2020

Conflito de interesses: inexistente

Suporte financeiro: não houve
} 